\title{
Fetal Programming of Infant Neuromotor Development: The Generation R Study
}

\author{
TAMARA vAN BATENBURG-EDDES, LAILA DE GROOT, ERIC A. P. STEEGERS, ALBERT HOFMAN, VINCENT W. V. JADDOE, \\ FRANK C. VERHULST, AND HENNING TIEMEIER
}

The Generation R Study Group [T.B.-E., V.W.V.J.]; Departments of Epidemiology [A.H., V.W.V.J., H.T.] and Obstetrics and Gynaecology [E.A.P.S.], Erasmus Medical Center, Rotterdam, 3000 CA, The Netherlands; Departments of Child and Adolescent Psychiatry

[T.B.-E., F.C.V., H.T.] and Pediatrics [V.W.V.J.], Erasmus Medical Center-Sophia Children's Hospital, Rotterdam, 3000 CB, The Netherlands; Department of Neonatology [L.G.], VU Medical Center, Amsterdam, 1007 MB, The Netherlands

\begin{abstract}
The objective of the study was to examine whether infant neuromotor development is determined by fetal size and body symmetry in the general population. This study was embedded within the Generation R Study, a population-based cohort in Rotterdam. In 2965 fetuses, growth parameters were measured in mid-pregnancy and late pregnancy. After birth, at age 9 to $15 \mathrm{wks}$, neuromotor development was assessed with an adapted version of Touwen's Neurodevelopmental Examination. Less optimal neuromotor development was defined as a score in the highest tertile. We found that higher fetal weight was beneficial to infant neurodevelopment. A fetus with a 1-SD score higher weight in mid-pregnancy had an $11 \%$ lower risk of less optimal neuromotor development (OR: 0.89; 95\% CI: 0.82-0.97). Similarly, a fetus with a 1-SD score larger abdominal-to-head circumference $(\mathrm{AC} / \mathrm{HC})$ ratio had a $13 \%$ lower risk of less optimal neuromotor development (OR: 0.87; 95\% CI: $0.79-$ 0.96). These associations were also present in late pregnancy. Our findings show that fetal size and body symmetry in pregnancy are associated with infant neuromotor development. These results suggest that differences in infant neuromotor development, a marker of behavioral and cognitive problems, are at least partly caused by processes occurring early in fetal life. (Pediatr Res 67: 132-137, 2010)
\end{abstract}

$\mathrm{N}$ euromotor development is an accepted means of measuring maturity of the CNS. It is a measure of brain development, which can be used at an early age. Most importantly, less optimal neuromotor development in infancy is a precursor of impaired motor functioning later in life (1) and can also be considered a marker for behavioral and cognitive problems $(2,3)$.

Neuromotor impairment in low birth weight infants can be caused by damage to the immature brain during delivery or by medical interventions performed after birth (4). However, it is more likely that deviances in the brain development originate before birth. A theory that relies on this

Received March 17, 2009; accepted September 15, 2009.

Correspondence: Henning Tiemeier, M.D., Ph.D., Department of Child and Adolescent Psychiatry, Erasmus MC-Sophia Children's Hospital, P.O. Box 2060, 3000 CB Rotterdam, The Netherlands; e-mail: h.tiemeier@erasmusmc.nl

The first phase of the Generation R Study is made possible by financial support from the Erasmus Medical Center, Rotterdam, the Erasmus University Rotterdam, and the Netherlands Organization for Health Research and Development (Zon Mw). The present study was supported by a grant from the Sophia Children's Hospital Foundation (project number 443). early origin is the "fetal programming hypothesis," which states that fetuses adapt to limited supplies of nutrition and oxygen. These adaptations program the fetus' physiology, metabolism, and growth, increasing the risk of later diseases; not only of cardiovascular diseases (5) but also of mental health problems $(6,7)$.

Most research on the fetal programming hypothesis has focused on the impact of low birth weight; the effects of normal variations in birth weight on later development are less clear, although several studies have investigated associations of birth weight with various outcomes in the general population $(8-10)$. Besides, there are only a few population-based studies that assessed fetal size during pregnancy (11). Commonly, birth weight is used as an indicator of fetal growth. However, birth weight does not provide information on patterns of growth at different stages in gestation. Different growth patterns may lead to differences in body proportions at birth. This symmetrical or asymmetrical growth has been associated with different risk factors for developing diseases $(12,13)$. While undergoing fetal growth restriction due to environmental influences, an individual fetus may still reach a normal birth weight because of his high genetic growth potential.

We measured fetal size in mid-pregnancy, in late pregnancy, and at birth and infant neuromotor development at the age between 9 and 15 wks. Furthermore, we conducted our study in the general population and investigated the neuromotor effects of variations in fetal size within the normal range. Smaller fetal size was expected to increase the risk of less optimal infant neuromotor development.

\section{METHODS}

Design and participants. This study was embedded within the Generation R Study, a population-based cohort from fetal life until young adulthood in the Netherlands. Briefly, all pregnant women who were resident in the city of Rotterdam at the time of their delivery and whose delivery data were between April 2002 and January 2006 were invited to participate (14). In this study, fetal size characteristics were assessed in 5621 fetuses in mid-pregnancy and

Abbreviations: AC/HC, abdominal-to-head circumference; ICC, Intraclass correlation coefficient 
in 5815 fetuses in late pregnancy. In 5507 fetuses, assessments were carried out both in mid-pregnancy and in late pregnancy. No neuromotor assessment was performed in 1641 infants because their mothers did not want a home visit $(n=1010,62 \%)$, were difficult to reach, and were visited when the infants were too old for a neuromotor assessment $(n=547,33 \%)$. Another $5 \%$ of these mothers could not be reached $(n=84)$. A neuromotor assessment was performed in 4288 infants, but 1323 infants were assessed outside the 9to 15-wk age range appropriate for Touwen's Neurodevelopmental Examination. Thus, 2965 infants were included in one or more analyses. The study was conducted in accordance with the guidelines proposed in the World Medical Association Declaration of Helsinki and has been approved by Medical Ethics Committee of the Erasmus Medical Center, Rotterdam. Written informed consent was obtained from all the participants.

Fetal ultrasound examinations and birth weight. Fetal ultrasound examinations were performed at the research centers in early pregnancy, midpregnancy, and late pregnancy. Ultrasound examinations in early pregnancy were used for establishing gestational age and could not be used in our analyses. For this study, gestational age-adjusted SD scores for abdominal circumference, head circumference, abdominal-to-head circumference (AC/ HC) ratio, as an indicator of asymmetrical fetal growth (12), and estimated fetal weight were used (15). In this study, the median (95\% range) gestational age for the fetal ultrasound examinations in mid-pregnancy was 20.4 (18.623.5) wks; in late pregnancy, it was 30.2 (28.5-32.9) wks. Intraobserver and interobserver reliability of fetal biometry measurements were assessed in early pregnancy; all intraobserver and interobserver intraclass correlation coefficients (ICCs) were above 0.982 (16). Infant birth weight was obtained from medical records completed by midwives and gynecologists.

Covariates. Postal questionnaires were used to obtain information on the mother's educational level, on her smoking and alcohol use during pregnancy, parity, family functioning, long-lasting difficulties, and also on ethnicity of the child. Obstetric and perinatal variables (gestational hypertension, gestational diabetes, preeclampsia, mode of delivery, sex, date of birth, and Apgar score after $1 \mathrm{~min}$ and after $5 \mathrm{~min}$ ) were obtained from midwife and hospital registries. Gestational age was determined by fetal ultrasound examinations and was used as it is distributed in the study population, including mostly infants born after a normal gestational age ( $37 \mathrm{wks}$ or more) and some infants born after a gestational age shorter than $37 \mathrm{wks}(<37 \mathrm{wks}, n=160 ;<34 \mathrm{wks}$, $n=31$ ). Infant's head circumference and height at the age of 1 mo were measured at the Dutch child health centers in the study area using standardized procedures. Maternal age and maternal and paternal anthropometrics were assessed at enrolment in one of the research centers. Antenatal and postnatal maternal anxiety and depression were assessed with the Brief Symptom Inventory (17). A score in the highest $15 \%$ was defined as being anxious or depressed (18).

Outcome: Neuromotor assessment. We selected age-appropriate items from Touwen's Neurodevelopmental Examination (19) and categorized all measured items in three groups: tone (24 items), responses (six items), and other observations (six items). Tone was assessed in several positionssupine, horizontal, vertical, prone, and sitting — and all items, such as adductor angle, were scored as normal, low, or high tone. Responses were assessed in supine (e.g. asymmetrical tonic neck reflex), vertical (e.g. Moro response), or prone position (e.g. Bauer response) and were scored as present, absent, or excessive. Other observations, such as following movements, were scored as present, absent, or excessive. A full description of the measured items has been published (20). An age-appropriate response was labeled "optimal." If the response indicated a delayed development, the response was labeled "nonoptimal." Scale values were calculated by summing the nonoptimal items. This resulted in a total score and three subscale scores: tone, responses, and other observations. As we studied a nonclinical population, the outcome measures were very skewed; neither square root nor log transformation could satisfactorily normalize the data. For this reason, we categorized the sum scores of the total and the subscales into tertiles, subsequently classifying the lowest and middle tertiles as optimal neuromotor development and the highest as less optimal. For the total scale, a subject with a less optimal neuromotor development, i.e. with a score in the highest tertile, was classified as such when they had a nonoptimal score on at least four items. Likewise, for the tone subscale, a subject had at least three nonoptimal scored items to be classified in the highest tertile. For the subscales measuring responses and other observations, one or more nonoptimal scored items resulted in classification in the highest tertile.

Moreover, we performed a reliability study to test the short-interval test-retest interobserver reliability and the interobserver reliability. The short-interval test-retest interobserver reliability test $(n=61)$ consisted of a first assessment by a research assistant, followed within 1 wk by a second assessment by another research assistant. For the interobserver reliability test $(n=76)$, two research assistants together went on a home visit in which they independently conducted two consecutive neuromotor assessments in the same child. The ICCs for the short-interval test-retest reliability and the interobserver reliability were 0.52 and 0.64 , respectively. The ICCs for the reliability of the neuromotor assessment were in the "modest" (0.41-0.60) to "substantial" (0.61-0.80) range (21), and in line with the study by Peters et al. (22) who reported a moderate to good reliability of modified Touwen examination. However, it is difficult to compare these values with a criterion because the ICC is influenced by features of the data, such as its variability (the ICC will be greater if the observations are more variable).

During a period of $\sim 3$ y (children were born between April 2002 and January 2006), neuromotor assessments were performed by, in total, 15 trained research assistants. Six of them participated in the reliability study. Furthermore, the trained research assistants were blinded for gestational age of the infants.

Statistical analyses. Chi-square tests and one-way ANOVA were used for a crude comparison between selected variables regarding infants with optimal and less optimal neuromotor development.

For this study, we did not use the original data obtained in mid-pregnancy, late pregnancy, and at birth, rather we used gestational age-adjusted SD scores of abdominal circumference, head circumference, $\mathrm{AC} / \mathrm{HC}$ ratio, estimated fetal weight, and birth weight.

By calculating the difference between the respective fetal size parameters in late and in mid-pregnancy, i.e. delta scores, we assessed fetal growth from mid-pregnancy to late pregnancy. Likewise, weight growth from late pregnancy until birth was assessed by calculating the difference between SD scores of birth weight and estimated fetal weight in late pregnancy. We checked whether the $90 \%$ CIs of the ORs for weight growth from midpregnancy to late pregnancy and from late pregnancy to birth overlapped. This is a crude but conservative test to estimate whether two ORs are different.

We calculated mean fetal size parameters for boys and girls. Pearson's correlation coefficients were calculated to determine the associations between fetal size parameters at one point in time, i.e. in mid-pregnancy and in late pregnancy. In addition, Pearson's correlation coefficients were calculated between the two time points for each fetal size parameter to determine the stability of an individual size measure relative to other children. The associations of fetal size and growth with infant neuromotor development were assessed using logistic regression analysis. All models were adjusted for gestational and postnatal age and infant's gender. We also present models adjusted for maternal educational level, smoking during pregnancy, maternal age, and ethnicity of the child. No other confounders were included in the analyses because these variables did not change the observed associations (change-in-estimate $<5 \%$ ). The conventional change-in-estimate criterion is a change of $10 \%$ or more (23). Because nonexperimental studies, like ours, are very sensitive to residual confounding, we used a more conservative changein-estimate criterion $(5 \%)$.

To determine whether the associations between fetal size and infant neuromotor development were independent of birth weight and postnatal size, we added birth weight, head circumference, and height at 1 mo to the fully adjusted models.

To check whether inclusion of preterm, growth-retarded infants, or infants whose mothers had preeclampsia, gestational hypertension, or gestational diabetes explained our findings, we repeated the analyses without: 1) infants born before 37 wks of gestation $(n=113), 2)$ infants with fetal size or symmetry parameters below the 10th percentile $(n=292)$, and 3$)$ infants whose mothers had preeclampsia, gestational hypertension, or diabetes $(n=135)$.

\section{RESULTS}

Excluded infants without a neuromotor assessment or with an assessment conducted too late were on average born earlier (mean gestational age $39.8 \mathrm{wks}$ ) and more often of non-Dutch origin $(44 \%)$, than included infants with complete data (mean gestational age 40.0 wks; $40 \%$ non-Dutch). Mothers of not included infants were lower educated (primary education $14 \%$ ), younger (mean age $29.5 \mathrm{y}$ ), and more often continued smoking during pregnancy (19\%), when compared with mothers of included infants (primary education 10\%; mean age 30.3 y; continued smoking 14\%; see Table 1).

Characteristics of the study population are presented in Table 2. Mothers of infants with less optimal neuromotor development were lower educated and younger than mothers of infants with optimal neuromotor development. Infants with less optimal neuromotor development were more often boys and of non-Dutch origin than those of infants with an optimal neuromotor development. 
Table 1. Comparison of included and excluded participants

\begin{tabular}{|c|c|c|}
\hline & $\begin{array}{l}\text { Included* } \\
(n=2965)\end{array}$ & $\begin{array}{l}\text { Excluded } \dagger \\
(n=2964)\end{array}$ \\
\hline \multicolumn{3}{|l|}{ Maternal characteristics } \\
\hline \multicolumn{3}{|l|}{ Educational level } \\
\hline Primary $(\%)$ & 10 & 14 \\
\hline Secondary $(\%)$ & 43 & 46 \\
\hline $\operatorname{High}(\%)$ & 48 & 40 \\
\hline$\chi^{2}(\mathrm{df})$ & & $40.4(2) \ddagger$ \\
\hline Age, y; mean $(\mathrm{SD})$ & $30.3(5.1)$ & $29.5(5.3)$ 韦 \\
\hline $\begin{array}{c}\text { Continued smoking during } \\
\text { pregnancy }(\%)\end{array}$ & 14 & $19 \ddagger$ \\
\hline \multicolumn{3}{|l|}{ Child characteristics } \\
\hline Male $(\%)$ & 49 & 51 \\
\hline Ethnicity, non-Dutch $(\%)$ & 40 & $44 末$ \\
\hline Gestational age, wks; mean (SD) & $40.0(1.6)$ & $39.8(1.8)$ 韦 \\
\hline $\begin{array}{l}\text { SD score abdominal circumference } \\
\text { in mid-pregnancy; mean (SD) }\end{array}$ & $0.05(0.95)$ & $0.02(1.02)$ \\
\hline $\begin{array}{l}\text { SD score head circumference in mid- } \\
\text { pregnancy; mean (SD) }\end{array}$ & $0.004(0.99)$ & $-0.03(1.03)$ \\
\hline $\begin{array}{l}\text { SD score } \mathrm{AC} / \mathrm{HC} \text { ratio in mid- } \\
\text { pregnancy; mean }(\mathrm{SD})\end{array}$ & $0.06(0.79)$ & $0.06(0.80)$ \\
\hline $\begin{array}{l}\text { SD score estimated fetal weight in } \\
\text { mid-pregnancy; mean (SD) }\end{array}$ & $-0.11(1.01)$ & $-0.08(0.96)$ \\
\hline SD score birth weight; mean (SD) & $-0.08(1.00)$ & $-0.13(1.04)$ \\
\hline
\end{tabular}

Values are percentages for categorical variables, means (SD) for continuous normal distributed variables.

Chi-square tests were used for categorical variables, ANOVA was used for continuous variables with a normal distribution.

* Included participants with at least one fetal size parameter in midpregnancy or in late pregnancy and neuromotor assessment at corrected age between 9 and 15 wks.

$\dagger$ Comprises 1641 eligible mothers with children who had a fetal size measurement but no neuromotor assessment and 1323 eligible mothers and children who had a neuromotor assessment out of the appropriate age range.

$\ddagger p<0.01$.

Table 3 presents SD scores of fetal size parameters in mid-pregnancy and late pregnancy for boys and girls. In mid-pregnancy and late pregnancy, boys had on average, a significantly larger abdominal circumference and head circumference than girls. In addition, in mid-pregnancy and in late pregnancy, the mean $\mathrm{AC} / \mathrm{HC}$ ratio was significantly smaller in boys than in girls.

Abdominal circumference and head circumference were moderately correlated in late pregnancy $(r=0.44)$. Also, abdominal circumference was moderately correlated with birth weight $(r=0.54)$. Abdominal circumference had a high correlation with both the $\mathrm{AC} / \mathrm{HC}$ ratio $(r=0.76)$ and an estimated fetal weight $(r=0.92)$. In contrast, head circumference had a negative correlation with $\mathrm{AC} / \mathrm{HC}$ ratio $(r=$ $-0.24)$ and was moderately correlated with estimated fetal weight and with birth weight $(r=0.45$ and $r=0.39$, respectively). The preceding late pregnancy correlation coefficients were highly similar in mid-pregnancy. Finally, fetal size parameters in mid-pregnancy were significantly correlated with the respective fetal size parameters in late pregnancy (minimum $r=0.30$, maximum $r=0.53$ ). Estimated fetal weight in mid-pregnancy and in late pregnancy was moderately correlated with birth weight $(r=0.27$ and $r=$ 0.57 , respectively).

Table 4 shows the associations between fetal size parameters and infant neuromotor development. These associations were of
Table 2. Sample characteristics

\begin{tabular}{|c|c|c|}
\hline & $\begin{array}{c}\text { Optimal } \\
\text { lowest-midst } \\
\text { tertile } \\
(n=1886)\end{array}$ & $\begin{array}{l}\text { Less optimal } \\
\text { highest tertile } \\
(n=1079)\end{array}$ \\
\hline \multicolumn{3}{|l|}{ Maternal characteristics } \\
\hline \multicolumn{3}{|l|}{ Educational level } \\
\hline Primary (\%) & 8 & 13 \\
\hline Secondary $(\%)$ & 42 & 44 \\
\hline High $(\%)$ & 50 & 43 \\
\hline$\chi^{2}(\mathrm{df})$ & & $27.5(2)^{*}$ \\
\hline Age, yrs; mean (SD) & $30.5(5.0)$ & $29.9(5.2)^{*}$ \\
\hline $\begin{array}{l}\text { Continued smoking during } \\
\text { pregnancy }(\%)\end{array}$ & 13 & 14 \\
\hline $\begin{array}{l}\text { Continued alcohol use during } \\
\text { pregnancy }(\%)\end{array}$ & 40 & $36^{*}$ \\
\hline Pregnancy complications (\%) & 5 & 5 \\
\hline Nulliparous (\%) & 56 & 57 \\
\hline $\begin{array}{l}\text { Prenatal maternal anxiety, score } \\
>15 \text { th percentile }(\%)\end{array}$ & 13 & $18^{*}$ \\
\hline $\begin{array}{l}\text { Prenatal maternal depression, score } \\
\quad>15 \text { th percentile }(\%)\end{array}$ & 14 & $18 \dagger$ \\
\hline $\begin{array}{l}\text { Postnatal maternal anxiety, score } \\
>15 \text { th percentile }(\%)\end{array}$ & 16 & 17 \\
\hline $\begin{array}{l}\text { Postnatal maternal depression, score } \\
\quad>15 \text { th percentile }(\%)\end{array}$ & 15 & 18 \\
\hline Height, cm; mean (SD) & $167.7(7.4)$ & $166.6(7.3)^{*}$ \\
\hline Height partner, cm; mean (SD) & $182.1(6.8)$ & $181.5(6.5) \dagger$ \\
\hline Body mass index, $\mathrm{kg} / \mathrm{m}^{2} ;$ mean (SD) & $24.5(4.2)$ & $24.6(4.3)$ \\
\hline $\begin{array}{l}\text { Body mass index partner, } \mathrm{kg} / \mathrm{m}^{2} \\
\text { mean }(\mathrm{SD})\end{array}$ & $25.2(3.0)$ & $25.0(3.0)$ \\
\hline \multicolumn{3}{|l|}{ Child characteristics } \\
\hline Male $(\%)$ & 47 & $52 *$ \\
\hline \multicolumn{3}{|l|}{ Ethnicity } \\
\hline Dutch, other Western (\%) & 63 & 57 \\
\hline Surinamese/Antillean (\%) & 12 & 12 \\
\hline Moroccan/Turkish (\%) & 12 & 19 \\
\hline Other non-Western (\%) & 14 & 13 \\
\hline$\chi^{2}(\mathrm{df})$ & & $28.0(3)^{*}$ \\
\hline $\begin{array}{l}\text { Postconceptional age, wks; } \\
\text { mean (SD) }\end{array}$ & $52.6(1.2)$ & $52.3(1.1)^{*}$ \\
\hline Gestational age, wks; mean (SD) & $40.0(1.5)$ & $40.0(1.7)$ \\
\hline Birth weight, $\mathrm{g}$; mean (SD) & $3456(511)$ & $3436(545)$ \\
\hline \multicolumn{3}{|l|}{ Way of birth } \\
\hline Spontaneous (\%) & 77 & 74 \\
\hline Instrumental $(\%)$ & 14 & 16 \\
\hline Caesarean section (\%) & 9 & 10 \\
\hline$\chi^{2}(\mathrm{df})$ & & $2.2(2)$ \\
\hline $\begin{array}{l}\text { Apgar } 1 \text { min, score }<25 \text { th } \\
\text { percentile }(\%)\end{array}$ & 26 & 27 \\
\hline $\begin{array}{l}\text { Apgar } 5 \text { min, score }<25 \text { th } \\
\text { percentile }(\%)\end{array}$ & 26 & 28 \\
\hline $\begin{array}{l}\text { Head circumference at } 1 \mathrm{mo}, \mathrm{cm} \text {; } \\
\text { mean }(\mathrm{SD})\end{array}$ & $37.5(1.3)$ & $37.6(1.4)$ \\
\hline Height at $1 \mathrm{mo}, \mathrm{cm}$; mean (SD) & $54.2(2.4)$ & $54.2(2.4)$ \\
\hline
\end{tabular}

Values are percentages for categorical variables, means (SD) for continuous normal distributed variables.

Chi-square tests were used for categorical variables, ANOVA was used for continuous variables with a normal distribution.

$* p<0.01$

$\dagger p<0.05$.

similar strength in mid-pregnancy and in late pregnancy. For a 1-SD score increase in abdominal circumference, the risk of less optimal neuromotor development was $11 \%$ lower (OR: 0.89; 95\% CI: 0.82-0.97). For each increase of 1-SD score in AC/HC ratio, the risk of less optimal neuromotor development was $13 \%$ 
Table 3. Fetal size by gender

\begin{tabular}{lcc}
\hline & $\begin{array}{c}\text { Boys } \\
(n=1454)\end{array}$ & $\begin{array}{c}\text { Girls } \\
(n=1511)\end{array}$ \\
\hline Mid-pregnancy SD scores fetal & & \\
$\quad$ size parameters & & \\
Abdominal circumference & $0.12(0.97)$ & $-0.01(0.93)^{*}$ \\
Head circumference & $0.16(0.98)$ & $-0.15(0.97)^{*}$ \\
Ratio AC/HC & $0.03(0.78)$ & $0.10(0.79)^{\dagger}$ \\
$\quad$ Estimated fetal weight & $-0.08(0.97)$ & $-0.08(0.94)$ \\
Late pregnancy SD scores fetal & & \\
$\quad$ size parameters & $0.11(0.95)$ & $-0.01(0.94)^{*}$ \\
Abdominal circumference & $0.30(0.94)$ & $-0.10(0.92)^{*}$ \\
Head circumference & $-0.09(0.77)$ & $0.03(0.75)^{*}$ \\
$\quad$ Ratio AC/HC & $0.10(0.97)$ & $0.07(0.95)$ \\
$\quad$ Estimated fetal weight & & \\
Delivery SD scores birth weight & $-0.08(1.02)$ & $-0.07(0.98)$ \\
$\quad$ Birth weight & \\
\hline$n=2965$ infants were included in one or more analyses. \\
Values are means (SD), ANOVA for continuous variables. \\
$* p<0.01$. & \\
$\dagger p<0.05$. &
\end{tabular}

Table 4. Associations between fetal size in mid-pregnancy and late pregnancy and infant neuromotor development

\begin{tabular}{|c|c|c|c|}
\hline & \multirow[b]{2}{*}{$\mathrm{N}$} & \multicolumn{2}{|c|}{$\begin{array}{l}\text { Risk of less optimal neuromotor } \\
\text { development at } 9-15 \mathrm{wks}\end{array}$} \\
\hline & & $\begin{array}{c}\text { Model I } \\
\text { OR (95\% CI) }\end{array}$ & $\begin{array}{c}\text { Model II } \\
\text { OR }(95 \% \text { CI })\end{array}$ \\
\hline \multicolumn{4}{|l|}{ Fetal size parameters } \\
\hline \multicolumn{4}{|c|}{ Mid-pregnancy } \\
\hline $\begin{array}{l}\text { Abdominal circumference, } \\
\text { per SD score }\end{array}$ & 2756 & $0.89(0.82-0.97)^{*}$ & $0.88(0.81-0.96)^{*}$ \\
\hline $\begin{array}{l}\text { Head circumference, } \\
\text { per SD score }\end{array}$ & 2753 & $0.99(0.92-1.08)$ & $0.99(0.92-1.08)$ \\
\hline $\begin{array}{l}\text { Ratio AC/HC, per SD } \\
\text { score }\end{array}$ & 2739 & $0.87(0.79-0.96)^{*}$ & $0.86(0.77-0.95)^{*}$ \\
\hline $\begin{array}{l}\text { Estimated fetal weight, } \\
\text { per SD score }\end{array}$ & 2749 & $0.89(0.82-0.97)^{*}$ & $0.89(0.82-0.97)^{*}$ \\
\hline \multicolumn{4}{|c|}{ Late pregnancy } \\
\hline $\begin{array}{l}\text { Abdominal circumference, } \\
\text { per SD score }\end{array}$ & 2854 & $0.93(0.86-1.00)$ & $0.92(0.85-1.00) \dagger$ \\
\hline $\begin{array}{l}\text { Head circumference, } \\
\text { per SD score }\end{array}$ & 2834 & $0.98(0.90-1.07)$ & $0.99(0.91-1.08)$ \\
\hline $\begin{array}{l}\text { Ratio AC/HC, per SD } \\
\text { score }\end{array}$ & 2829 & $0.92(0.83-1.02)$ & $0.90(0.81-1.00) \dagger$ \\
\hline $\begin{array}{l}\text { Estimated fetal weight, } \\
\text { per SD score }\end{array}$ & 2850 & $0.92(0.85-1.00) \dagger$ & $0.92(0.85-1.00) \dagger$ \\
\hline \multicolumn{4}{|l|}{ Birth } \\
\hline $\begin{array}{l}\text { Birth weight, per } \\
\text { SD score }\end{array}$ & 2891 & $0.95(0.88-1.02)$ & $0.95(0.88-1.03)$ \\
\hline
\end{tabular}

$n=2965$ infants were included in one or more analyses.

Model I: logistic regression analyses adjusted for gender child, and gestational and postnatal age.

Model II: logistic regression analyses additionally adjusted for educational level, smoking and age mother, and ethnicity of the child.

$* p<0.01$

$\dagger p<0.05$

less (OR: 0.87; 95\% CI: 0.79-0.96). The risk of less optimal neuromotor development was $11 \%$ lower for a 1-SD score increase in estimated fetal weight (OR: 0.89; 95\% CI: 0.82-0.97). Adjusting for sex, gestational and postnatal age, or adding the mother's educational level, age and smoking behavior during pregnancy, and infant's ethnicity resulted in approximately the same effect estimates (Table 4). Exclusion of preterm infants
Table 5. Associations between fetal growth and infant neuromotor development

\begin{tabular}{|c|c|c|}
\hline & $\mathrm{N}$ & $\begin{array}{c}\text { Risk of less optimal } \\
\text { neuromotor development } \\
\text { at } 9-15 \mathrm{wks} \\
\text { OR }(95 \% \mathrm{CI})\end{array}$ \\
\hline \multicolumn{3}{|l|}{$\begin{array}{l}\text { Fetal growth parameters from } \\
\text { mid-pregnancy to late pregnancy }\end{array}$} \\
\hline $\begin{array}{l}\text { Abdominal circumference, per SD } \\
\text { score }\end{array}$ & 2703 & $1.05(0.97-1.14)$ \\
\hline Head circumference, per SD score & 2682 & $1.00(0.92-1.08)$ \\
\hline Ratio AC/HC, per SD score & 2664 & $1.05(0.96-1.15)$ \\
\hline $\begin{array}{l}\text { Estimated fetal weight, per SD } \\
\text { score }\end{array}$ & 2692 & $1.05(0.96-1.14)$ \\
\hline \multicolumn{3}{|l|}{$\begin{array}{l}\text { Weight growth from late pregnancy } \\
\text { to birth }\end{array}$} \\
\hline Weight, per SD score & 2841 & $1.03(0.94-1.12)$ \\
\hline
\end{tabular}

Delta scores, i.e. difference between late and mid-pregnancy or between birth and late pregnancy 2721 of 2965 had fetal size measurements in mid-pregnancy and in late pregnancy.

Logistic regression analyses adjusted for gender child, and gestational and postnatal age, educational level, smoking and age mother, and ethnicity of the child.

( $<37$ wks of gestation), infants with a fetal size parameter below the 10th percentile or infants whose mothers had preeclampsia, gestational hypertension, or diabetes also did not change the results (data not shown).

As effects were very similar in mid-pregnancy and in late pregnancy, it followed that infant's neuromotor development was not influenced by fetal growth from mid-pregnancy to late pregnancy. In addition, there was no effect of weight growth from late pregnancy until birth on infant neuromotor development (Table 5). It is unlikely that the ORs for the two weight growth periods are significantly different because the $90 \%$ CIs were very similar $(90 \%$ CI for weight growth from mid-pregnancy to late pregnancy $0.97-1.13$; 90\% CI for weight growth from late pregnancy until birth $0.96-1.11$ ).

Adding birth weight, head circumference, and height at 1 mo to the fully adjusted models did not change the effect estimates for the associations between fetal size in midpregnancy and infant neuromotor development. The odds ratio for the association between abdominal circumference and infant neuromotor development was not at all affected by this additional adjustment (OR: 0.88; 95\% CI: 0.81-0.96). With each 1-SD increase in $\mathrm{AC} / \mathrm{HC}$ ratio, the risk of less optimal neuromotor development was $13 \%$ lower (OR: 0.87; 95\% CI: $0.78-0.96)$, which corresponds to an only very marginally reduced effect. Likewise, with a 1-SD increase of estimated fetal weight (OR: 0.89; 95\% CI: 0.82-0.97), the observed risk of less optimal neuromotor development was $11 \%$ less, which was exactly the same as without the additional adjustment. In addition, the associations between fetal size in late pregnancy and infant neuromotor development were independent of birth weight and postnatal infant anthropometrics (data not shown).

\section{DISCUSSION}

This study shows that a fetus with a lower body weight or with asymmetrical growth is more likely to have less optimal neuromotor development in infancy. Already in mid- 
pregnancy, body size predicted a poorer neuromotor development. These associations were also present in late pregnancy. Fetal size and body symmetry predicted infant neuromotor development independent of birth weight and postnatal growth.

Neuromotor development is a measure of maturation of the CNS and an indirect indication of brain dysfunction $(24,25)$. Brain structures begin to form in the first weeks after conception and the brain is thus from early pregnancy onward vulnerable to damaging influences (26). As the brain develops throughout pregnancy, adverse factors impairing fetal growth, such as placental insufficiency, could negatively affect the development of the CNS continuously during pregnancy.

Harvey et al. (27) found that small for gestational age babies with prolonged growth impairment beginning before $26 \mathrm{wks}$ of gestation $(n=10)$ more often had poor perceptual performance and motor ability at the age of $5 \mathrm{y}$. This, like our results, suggests that differences in neuromotor development are, at least partly, caused by processes occurring early in fetal life, although the results of this study cannot be compared directly with the results of our study. In addition, our results show that differences in infant neuromotor development are explained by fetal size and body symmetry within the normal range.

Most population-based studies on the effects of intrauterine growth restriction are performed in high-risk populations. Typically, differences in neuromotor outcomes between a high-risk group and a low-risk group are investigated $(28,29)$. We conducted our study in the general population with only few growth-retarded infants. Nevertheless, we found that fetal size and body symmetry were associated with the infant's neuromotor development; excluding infants born preterm ( $<37$ wks), with a fetal size or body symmetry parameter below the 10th percentile or infants whose mothers had preeclampsia, gestational hypertension, or gestational diabetes did not change our findings. This suggests significant linear trends across continuous distributions.

There are several possible mechanisms that may underlie the associations between fetal size and body symmetry and infant neuromotor development. First, according to the fetal programming hypothesis, malnutrition in mid-pregnancy or late pregnancy could play a crucial role in fetal growth (5). The main characteristic of fetal growth is cell division, which occurs at a high pace and depends on nutrition and oxygen. When a lack of nutrition and oxygen occurs, the fetus adapts and slows its rate of cell division, especially in organs that go through a critical period at that time. Consequently, this reduces the number of cells in particular organs $(30,31)$, which may also affect growth or size of the brain and with that influences neuromotor functioning after birth. We did not find that growth from mid-pregnancy until birth affected neuromotor development but found only that fetal size and body symmetry in mid-pregnancy were related to infant neuromotor development. This may indicate that smaller fetuses in midpregnancy continue to be smaller throughout pregnancy and that these fetuses have an increased risk of less optimal neuromotor development in infancy.

Another mechanism that may explain the association of fetal size and body symmetry and infant neuromotor function- ing is the regulation of the maternal stress system, in particular the hypothalamic pituitary adrenal axis. Several studies have suggested that antenatal maternal distress impacts on both fetal growth and infant neuromotor development (32). Because adjusting for antenatal maternal symptoms of anxiety and depression did not change our effect estimates, it is unlikely that this mechanism accounts for a substantial part of our findings.

Third, a shared genetic factor may underlie the association between fetal growth and neuromotor development. The association between maternal length and maternal weight and the offspring's birth weight is in part explained by genetic influences $(33,34)$. It is also known that maternal height and weight have a genetic influence on neuromotor functioning (35). Against this background, we considered maternal height and weight as potential confounders. However, they had no influence on the observed associations. The observed link between fetal growth and neuromotor development can thus only be explained by genetic factors unrelated to maternal anthropometrics.

The AC/HC ratio has been shown to be useful in distinguishing symmetrical from asymmetrical growth (12). Asymmetrical growth suggests that the fetus has a relatively large head circumference compared with its abdominal circumference. The measure is used as an indicator of fetal blood flow redistribution. Although head circumference by definition is less affected, it does not mean that brain development is unimpaired. A study by Duncan et al. (36) showed that the brain growth slowed well before growth of head circumference in cases of impaired fetal development. Also, Scherjon $e t$ al. (37) found poorer cognitive functioning when circulatory adaptation in fetuses occurred. In this study, we found that head circumference in mid-pregnancy and in late pregnancy was not associated with infant neuromotor development, whereas smaller abdominal circumference, $\mathrm{AC} / \mathrm{HC}$ ratio, and estimated fetal weight resulted in less optimal neuromotor development in infancy.

A major strength of this study is that both determinants and outcome were measured by trained sonographers and research nurses and were not reported by the mother. Furthermore, this study is embedded in a large population-based cohort study, which enabled us to adjust for a large number of confounders. Although selection of these covariates was based on previous studies, only few of them influenced the associations under study. Finally, the multiethnic composition of our study population may reduce generalizability of the results to the general Dutch population, but certainly makes the results more generalizable to countries with non-Western populations. Moreover, adjusting for ethnicity did not attenuate the significant associations between fetal size and infant neuromotor development. This suggests that the results may even be relatively independent of ethnicity.

Several methodological limitations need to be discussed. First, selective nonresponse could have influenced our results, e.g. if participants with impaired grown fetuses were more likely than nonparticipants to have an infant with less optimal neuromotor development. However, because participants were blinded for the associations under study, and because we are 
studying the effects of subtle differences in fetal growth, it is unlikely that selective nonresponse substantially influenced our findings. Second, because fetal ultrasound examinations in early pregnancy were used to establish gestational age, we were not able to assess the relation between early fetal size and infant neuromotor development. Furthermore, any error in the estimation of gestational age may reduce the variance of infant neuromotor development explained by fetal size. Third, as we studied a nonclinical population, neuromotor measures were very skewed and could not be normalized by statistical transformations. Therefore, the scale scores were categorized, resulting in less power for analyses. Finally, although our associations were influenced by only few of the many measured potential confounders, we cannot exclude that residual confounding partly explains our results.

This study shows that, in the general population, fetal size and body symmetry in mid-pregnancy and in late pregnancy are associated with infant neuromotor development. Taking account of several influential confounders did not attenuate these significant associations. This study suggests that differences in neuromotor development are, at least partly, caused by processes occurring early in fetal life. Although the effects of fetal size variations on infant neuromotor development were modest and could not be interpreted clinically very easily, they may well have impact on population level. In addition, these effects may shed light on mechanisms underlying optimal child development. Future research is necessary to determine whether the negative effects of impaired fetal growth on infant neuromotor functioning are transient, persistent, or progressive.

Acknowledgments. The Generation R Study is conducted by the Erasmus Medical Center, Rotterdam in close collaboration with the School of Law and Faculty of Social Sciences of the Erasmus University Rotterdam, the Municipal Health Service Rotterdam area, the Rotterdam Homecare Foundation, and the Stichting Trombosedienst and Artsenlaboratorium Rijnmond (STAR), Rotterdam. We acknowledge the contribution of participating mothers and their children, general practitioners, hospitals, midwives, and pharmacies in Rotterdam.

\section{REFERENCES}

1. Samsom JF, de Groot L, Bezemer PD, Lafeber HN, Fetter WP 2002 Muscle power development during the first year of life predicts neuromotor behaviour at 7 years in preterm born high-risk infants. Early Hum Dev 68:103-118

2. Davis NM, Ford GW, Anderson PJ, Doyle LW 2007 Developmental coordination disorder at 8 years of age in a regional cohort of extremely-low-birthweight or very preterm infants. Dev Med Child Neurol 49:325-330

3. Pine DS, Wasserman GA, Fried JE, Parides M, Shaffer D 1997 Neurological soft signs: one-year stability and relationship to psychiatric symptoms in boys. J Am Acad Child Adolesc Psychiatry 36:1579-1586

4. Whitaker AH, Feldman JF, Lorenz JM, Shen S, McNicholas F, Nieto M, McCulloch D, Pinto-Martin JA, Paneth N 2006 Motor and cognitive outcomes in nondisabled low-birth-weight adolescents: early determinants. Arch Pediatr Adolesc Med 160:1040-1046

5. Barker DJ 1995 Fetal origins of coronary heart disease. BMJ 311:171-174

6. St Clair D, Xu M, Wang P, Yu Y, Fang Y, Zhang F, Zheng X, Gu N, Feng G, Sham $\mathrm{P}, \mathrm{He}$ L 2005 Rates of adult schizophrenia following prenatal exposure to the Chinese famine of 1959-1961. JAMA 294:557-562

7. Susser E, Neugebauer R, Hoek HW, Brown AS, Lin S, Labovitz D, Gorman JM 1996 Schizophrenia after prenatal famine. Further evidence. Arch Gen Psychiatry $53: 25-31$
8. Shenkin SD, Starr JM, Deary IJ 2004 Birth weight and cognitive ability in childhood: a systematic review. Psychol Bull 130:989-1013

9. Pearce MS, Deary IJ, Young AH, Parker L 2005 Growth in early life and childhood IQ at age 11 years: the Newcastle Thousand Families Study. Int J Epidemiol 34:673-677

10. Kirkegaard I, Obel C, Hedegaard M, Henriksen TB 2006 Gestational age and birth weight in relation to school performance of 10-year-old children: a follow-up study of children born after 32 completed weeks. Pediatrics 118:1600-1606

11. Gale CR, O'Callaghan FJ, Godfrey KM, Law CM, Martyn CN 2004 Critical periods of brain growth and cognitive function in children. Brain 127:321-329

12. Campbell S, Thoms A 1977 Ultrasound measurement of the fetal head to abdomen circumference ratio in the assessment of growth retardation. Br J Obstet Gynaecol 84:165-174

13. Rasmussen S, Kiserud T, Albrechtsen S 2006 Foetal size and body proportion at $17-19$ weeks of gestation and neonatal size, proportion, and outcome. Early Hum Dev 82:683-690

14. Jaddoe VW, van Duijn CM, van der Heijden AJ, Mackenbach JP, Moll HA, Steegers EA, Tiemeier H, Uitterlinden AG, Verhulst FC, Hofman A 2008 The Generation R Study: design and cohort update until the age of 4 years. Eur J Epidemiol 23:801811

15. Hadlock FP, Harrist RB, Carpenter RJ, Deter RL, Park SK 1984 Sonographic estimation of fetal weight. The value of femur length in addition to head and abdomen measurements. Radiology 150:535-540

16. Verburg BO, Mulder PG, Hofman A, Jaddoe VW, Witteman JC, Steegers EA 2008 Intra- and interobserver reproducibility study of early fetal growth parameters. Prenat Diagn 28:323-331

17. de Beurs E 2004 Brief Symptom Inventory, Handleiding. Pits Publishers, Leiden, The Netherlands

18. O'Connor TG, Heron J, Glover V 2002 Antenatal anxiety predicts child behavioral/ emotional problems independently of postnatal depression. J Am Acad Child Adolesc Psychiatry 41:1470-1477

19. Touwen B 1976 Neurological Development in Infancy. Mac Keith Press, London, pp $28-126$

20. van Batenburg-Eddes T, de Groot L, Huizink AC, Steegers EA, Hofman A, Jaddoe VW, Verhulst FC, Tiemeier H 2009 Maternal symptoms of anxiety during pregnancy affect infant neuromotor development: The Generation R Study. Dev Neuropsychol 34:476-493

21. Cohen J 1968 Weighted kappa; nominal scale agreement with provision for scaled disagreement or partial credit. Psychol Bull 70:213-220

22. Peters LH, Maathuis KG, Kouw E, Hamming M, Hadders-Algra M 2008 Test-retest, inter-assessor and intra-assessor reliability of the modified Touwen examination. Eur J Paediatr Neurol 12:328-333

23. Mickey RM, Greenland S 1989 The impact of confounder selection criteria on effect estimation. Am J Epidemiol 129:125-137

24. Prechtl HF 1977 The Neurological Examination of the Full-term Newborn Infant Cambridge University Press, London, pp 1-8

25. Touwen BC 1979 Examination of the child with minor neurological dysfunction Clinics in Developmental Medicine. 2nd ed. William Heinemann Medical Books, London

26. Rice D, Barone S Jr 2000 Critical periods of vulnerability for the developing nervous system: evidence from humans and animal models. Environ Health Perspect 108:511-533

27. Harvey D, Prince J, Bunton J, Parkinson C, Campbell S 1982 Abilities of children who were small-for-gestational-age babies. Pediatrics 69:296-300

28. Hoff Esbjorn B, Hansen BM, Greisen G, Mortensen EL 2006 Intellectual development in a Danish cohort of prematurely born preschool children: specific or general difficulties? J Dev Behav Pediatr 27:477-484

29. Mikkola K, Ritari N, Tommiska V, Salokorpi T, Lehtonen L, Tammela O, Paakkonen L, Olsen P, Korkman M, Fellman V 2005 Neurodevelopmental outcome at 5 years of age of a national cohort of extremely low birth weight infants who were born in1996-1997. Pediatrics 116:1391-1400

30. Widdowson EM, McCance RA 1975 A review: new thoughts on growth. Pediatr Res 9:154-156

31. McCance RA, Widdowson EM 1974 The determinants of growth and form. Proc R Soc Lond B Biol Sci 185:1-17

32. Huizink AC, Robles de Medina PG, Mulder EJ, Visser GH, Buitelaar JK 2003 Stress during pregnancy is associated with developmental outcome in infancy. J Child Psychol Psychiatry 44:810-818

33. Griffiths LJ, Dezateux C, Cole TJ 2007 Differential parental weight and height contributions to offspring birthweight and weight gain in infancy. Int J Epidemiol 36:104-107

34. Knight B, Shields BM, Turner M, Powell RJ, Yajnik CS, Hattersley AT 2005 Evidence of genetic regulation of fetal longitudinal growth. Early Hum Dev 81:823831

35. Peter I, Vainder M, Livshits G 1999 Genetic analysis of motor milestones attainment in early childhood. Twin Res 2:1-9

36. Duncan KR, Issa B, Moore R, Baker PN, Johnson IR, Gowland PA 2005 A comparison of fetal organ measurements by echo-planar magnetic resonance imaging and ultrasound. BJOG 112:43-49

37. Scherjon S, Briet J, Oosting H, Kok J 2000 The discrepancy between maturation of visual-evoked potentials and cognitive outcome at five years in very preterm infants with and without hemodynamic signs of fetal brain-sparing. Pediatrics 105:385-391 